EDUCATIONAL

- RESOURCE

Volume 11 Issue 12019

DOI: 10.21315/eimj2019.11.1.8

ARTICLE INFO

Submitted: 08-01-2019

Accepted: 15-02-2019

Online: 29-03-2019

\title{
Ten Questions to be Answered before Incorporating Problem-Based Learning (PBL) into Professionalism Course
}

\author{
Kamran Sattar \\ Department of Medical Education, School of Medical Sciences, \\ Universiti Sains Malaysia, Kelantan, MALAYSIA
}

To cite this article: Sattar K. Ten questions to be answered before incorporating problem-based learning (PBL) into professionalism course. Education in Medicine Journal. 2019;11(1):59-69. https://doi.org/10.21315/eimj2019.11.1.8

To link to this article: https://doi.org/10.21315/eimj2019.11.1.8

\begin{abstract}
Professionalism is considered as one of the most inspiring as well as challenging proficiency to teach and evaluate, because of its multifaceted and context-specific nature. This paper defines an orderly and useful escort on how to incorporate the problem-based learning (PBL) as a teaching and assessing modality, within a course of medical professionalism. While answering Harden's 10 questions, course planners shall find this approach doable, allowing them to design and utilising this in an undergraduate medical education context. An enlightening approach, as this will prepare our students to be future professional doctors, equipped with all necessary professionalism attributes, in our fast varying professional environment.
\end{abstract}

Keywords: Medical professionalism, Teaching and assessment, PBL, Undergraduate medical students School of Medical Sciences, Universiti Sains Malaysia, 16150 Kubang Kerian, Kelantan, Malaysia | Email: drkamransattar@student.usm.my

\section{INTRODUCTION}

Professionalism is all about attributes, behaviours and commitments, which characterise a profession. A deliberate inculcation of attributes, behaviours and commitments (ABC) of professionalism is essentially required in medical education (Figure 1). It is for every student; at any phase of the medical education. In the past, it was assumed that professionalism is dispersed inactively to the students through "the hidden curriculum," leaving a lot to chance. However, over time, it has been believed and supported that medical students need to be formally taught and trained in the concepts of professionalism. In this paper, we propose a problem- based learning (PBL) approach for professionalism, tailor-made in conjunction with Harden's 10 questions. These 10 questions are significant in various situations where a course or curriculum is intended to be planned, including an undergraduate degree course (1).

Professionalism is described as "establishing those attitudes and behaviours that serve to preserve patient interest above [physician] self-interest," and "exhibiting values, beliefs and attitudes that put the needs of another above your own needs" $(2,3)$. Widespread literature concludes professionalism to be one of the most challenging competencies to define, teach and evaluate (4-6). 
PBL uses cases that involve "real-world" problems and necessitate students to attain new knowledge to resolve the problem. PBL is student-centred therefore, the pursuit for more information drives student learning in a shared, group-centred, hands-on setting (7). Within PBL sessions, two major pedagogical ideologies stimulate students acquire best knowledge; (a) they are more active in groups rather than alone, and (b) they are able to enthusiastically identify and tackle the gaps in their knowledge. Information gathered in this study aims to highlight the issues to be considered while selecting PBL sessions to improve professionalism course implementation as well as teaching and assessment material. We, therefore intend to find answers to the following questions in pursuit to get evidence to best fit PBL into the professionalism course.

\section{THE 10 QUESTIONS}

\section{Ask Yourself, "What are the Needs in Relation to the Product of the Training Programme?"}

There is a mounting requirement and awareness among the community to have doctors who, throughout their professional lives are talented and proficient enough for exhibiting a conduct, cherished, with the set of distinguishable positive qualities or behaviours. These behaviours are termed as professionalism when it comes to a certain profession. Such binding demands upon medical profession have been greatly amplified due to variations in the traditional modes of health care conveyance, increased complexity in the doctor-patient relationship ever since the advent of prevalent practised and advocated patients' right with medicolegal rulings. Generally, however, doctors' professionalism is meticulously dissected.

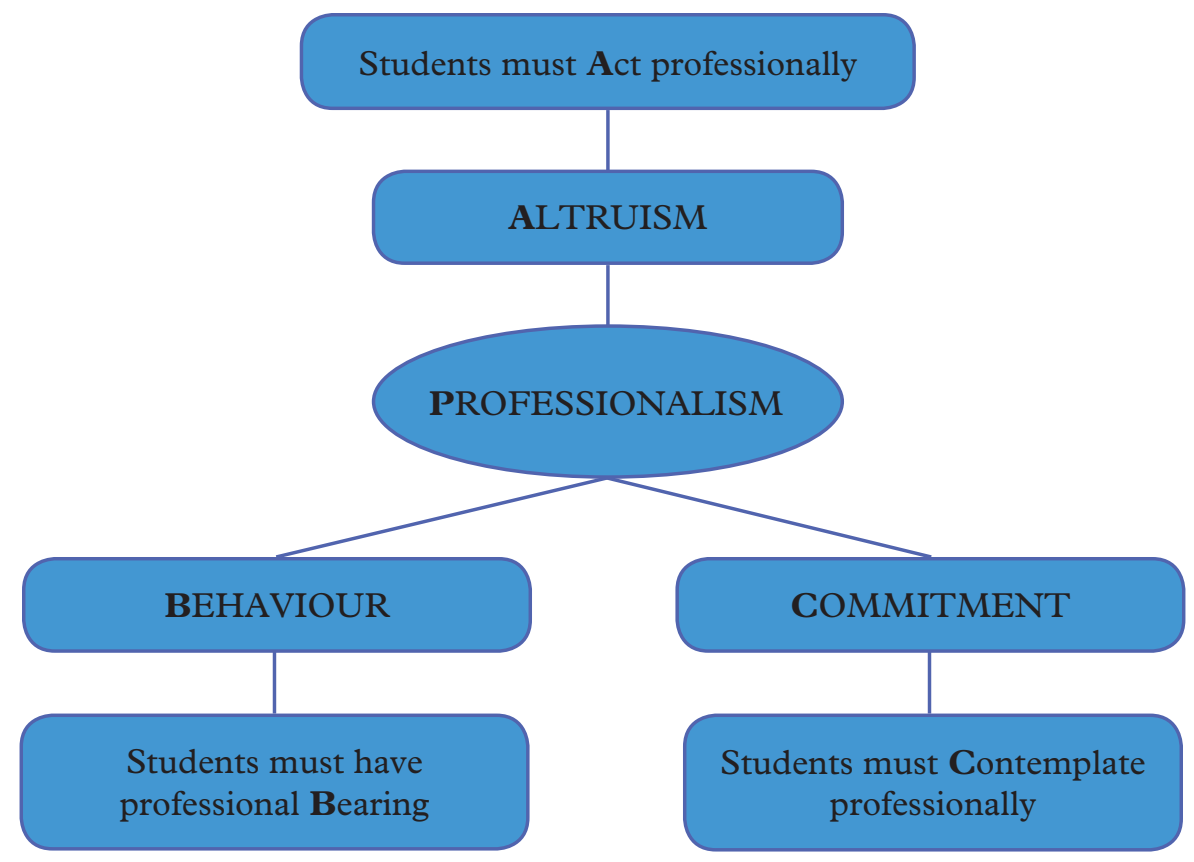

Figure 1: $A B C$ of professionalism to be learnt by students during the course. 
The public's expectations of doctors are high and criticisms of shortcoming harsh. In today's information-rich world, patients are more well-informed and demanding than ever. So, professionals are very often held to account. Interestingly, patients' complaints often instigate not from doctors' ability to treat diseases, but from unprofessional conduct (8).

\section{Ask Yourself, "What are the Aims and Objectives?"}

Objectives must be designed in a way that reflect the learners' needs according to their academic stage. Therefore, Table 1 is an example of a course "Professionalism in Medicine, for undergraduate students".

\section{Ask Yourself, "What Content Should be Included?"}

Believing that professionalism is to be built around the three-way framework of (a) fundamental information and skills, (b) ethical principles, and (c) altruism. Therefore, the content to be incorporated within the course of professionalism in medicine shall comprise (including but not limited to) the set of behaviours which in turn shall enable them to:

i. Observe the high moral standards.

ii. Respond to societal requirements.

iii. Exhibit honesty and integrity, beneficence and respect for all.

iv. Exercise accountability.

Table 1: Example of aims and objectives of the course "Professionalism in Medicine"

\begin{tabular}{|c|c|}
\hline Aims & Objectives \\
\hline $\begin{array}{l}\text { (Conceptual knowledge) } \\
\text { To inspire the students to grasp the } \\
\text { concept of Professionalism. }\end{array}$ & $\begin{array}{l}\text { - To define the core elements of the profession and } \\
\text { professionalism. } \\
\text { - To deepen the understanding of the moral dimensions in } \\
\text { the practice of medicine. } \\
\text { - To recognise the evolution of medical professionalism over } \\
\text { the history. } \\
\text { - To recognise, critically analyse, and resolve the } \\
\text { professionalism issues that may arise in their practice of } \\
\text { health care. }\end{array}$ \\
\hline $\begin{array}{l}\text { (Attitudinal) } \\
\text { To motivate the students for acquiring } \\
\text { and understanding the values and } \\
\text { attributes related to Professionalism. }\end{array}$ & $\begin{array}{l}\text { - To incorporate the values and attributes of professionalism } \\
\text { into the medical students' perspective. } \\
\text { - To respect the role of professional medical student and } \\
\text { health professionals in health promotion and community } \\
\text { development. } \\
\text { - To weigh the cost of being unprofessional and the legal } \\
\text { aspects inherent to the medical profession. }\end{array}$ \\
\hline $\begin{array}{l}\text { (Discipline-related knowledge and } \\
\text { skills) } \\
\text { To guide the students into acting } \\
\text { and behaving along the guidelines of } \\
\text { Professionalism. }\end{array}$ & $\begin{array}{l}\text { - To promote professional and ethical behaviour that } \\
\text { addresses the interests of patients and society first, } \\
\text { likewise serving the interests of the profession. } \\
\text { - To demonstrate sensitivity and responsiveness to others' } \\
\text { culture, age, gender and disabilities. }\end{array}$ \\
\hline $\begin{array}{l}\text { (Personal transferable skills) } \\
\text { To refine the personal skills and reach } \\
\text { the highest standards of Professionalism } \\
\text { by knowing how to use them. }\end{array}$ & $\begin{array}{l}\text { - To understand the psychological aspects related to human } \\
\text { nature, including, personalities, illness behaviour, stress } \\
\text { management, learning patterns and developing skills. } \\
\text { - To develop and refine the interpersonal relationships. } \\
\text { - To develop decision-making skills that will contribute to } \\
\text { students' ethical behaviour. }\end{array}$ \\
\hline
\end{tabular}


v. Demonstrate self-obligation to excellence.

vi. Parade a pledge to scholarship and to progressing their field.

vii. Deal in complex circumstances.

viii. Reflect upon actions.

PBL (4 sessions a week and 60 min each, modifiable according to available slots in the curriculum as well as the prefixed credit/ contact hours).

To motivate and persuade the students in obtaining the deep understanding of identifiable positive talents with the focus on their existing level of understanding, following is an example of a problem scenario.

\section{Problem scenario:}

\section{Trigger}

You are a medical student (Year 2) preparing very hard for the coming (tomorrow) exam.

Today 'Mr. A' (one of your classmates) who always skips the classes and never seems to be serious for his exams, meets you in the library and shows you a paper containing questions for the next day exam and asks for a handsome amount if you need this question paper.

\section{Discussion questions}

1. List the key information about ' $\mathrm{Mr}$. A'.

2. List the information about 'Mr. A' usual behaviour for his studies and his offer.

3. How would you handle this kind of situation?

4. What concerns are to be considered significant in coming to a decision about what to do?
Tutor's role: (organise, manage and sustain)

Once PBL is designated as the suitable teaching and learning method with specific objectives, a tutor has to list all compulsory and available resources, e.g.:

i. A proper room with whiteboards, flip charts, markers and chairs that are organised in a circular fashion.

ii. Computer/web/internet resources.

iii. Prescribed textbook (if available), e.g. Spandorfer J, Pohl CA, Rattner SL, Nasca TJ. Professionalism in medicine: a case-based guide for medical students. UK: Cambridge University Press; 2010.

iv. Related journal articles (can be made available from PubMed).

v. Students' study guide: to give tips on refining PBL group progression and gathering feedback on assessment tools. Additionally, this guide must outline learning objectives.

Furthermore, tutor shall remember that instead of providing information he/she must act as, a facilitator allowing students to seek out information for themselves. Another important role of the tutor is the provision of appropriate feedback and assistance that helps and stimulates the students towards active learning. He/she needs to make sure all the students are involved. Fellow students in the group are also educational resources as students learn from each other. At the end of PBL, it is inevitable to carry out evaluation and present the reflection to the students in the form of an explicit feedback.

\section{Ask Yourself, "How the Content Should be Organised?"}

Move and build up knowledge (building block approach) gradually so that the learning may be enduring as shown in Figure 2. 


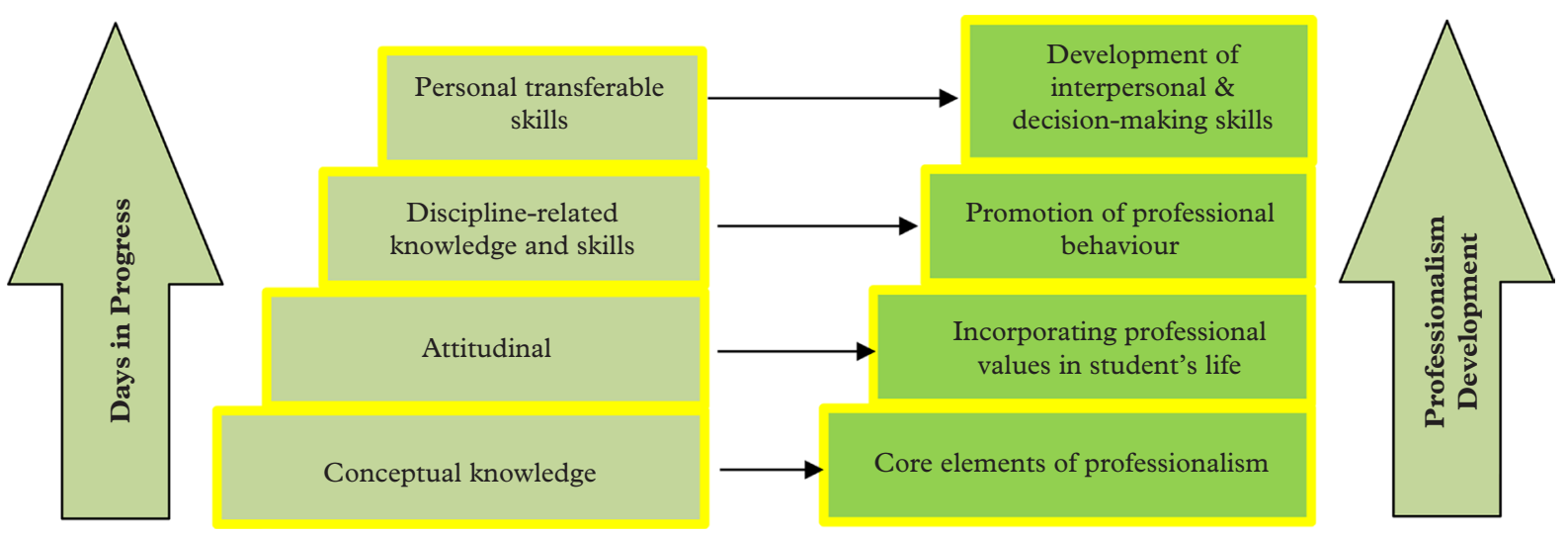

Figure 2: Content ogranisation.

\section{Ask Yourself, "What Educational Strategies Should be Adopted?"}

Contingent to the essential content, and the specific course objectives, learner-centred approach is best to be adopted. Moreover, self-directed learning, additionally ensures nurturing of knowledge process principally for the fruitful continuum during this course, because it serves as the most operational tactic for the continuum of medical education, particularly when learning is based on experience, and new knowledge and understanding is targeted to be assimilated into the personal and professional context of the individual (9). It is, therefore, recommended that component of PBL (relating to a range of topics directly relevant to professional educational climate shall be incorporated within the professionalism course) with the students' involvement at all levels ranging from the understanding of basic concepts of their application. Harden's SPICES model (10) for educational strategies in curriculum development (Table 2) best suits in such a situation.

\section{Ask Yourself, "What Teaching Methods Should be Used?"}

Other than the independent/self-study, which remains an essential component of any course, the small group learning shall constitute the main bulk for educational activities in the course. The teaching sessions should be student-centred with the provision of non-threatening educational environment where students develop and utilise the problem-solving skills. Details of such sessions are given in the above section (PBL).

Table 2: Checklist for the course using SPICES model approach

\begin{tabular}{lclc}
\hline Student-centered & $\sqrt{ }$ & Teacher-centered & $\times$ \\
Problem solving & $\sqrt{ }$ & Information gathering & $\times$ \\
Integrated & $\sqrt{ }$ & Discipline-based & $\times$ \\
Community-based & $\sqrt{ }$ & Hospital-based & $\times$ \\
Elective & $\sqrt{ }$ & Standard-program & $\times$ \\
Systematic & $\sqrt{ }$ & Apprenticeship-based & $\times$ \\
\hline \multicolumn{4}{c}{ More the green checks, better the course is. } \\
\\
Adopted from SPICES Model
\end{tabular}




\section{Ask Yourself, "How Assessment Should be Carried Out?"}

Tables 3 and 4 present the checklist for (a) Tutor assessment of students and (b) Selfassessment, respectively and each checklist correspond to the objectives of PBL, i.e. knowledge application, critical thinking, independent study and teamwork. This, in turn, shall help align the PBL assessment with curricular goals and course learning objectives, rendering validity of assessment to be improved and subjectivity across instructors' evaluations shall be lessened (10). The tutor is responsible for the feedback and to ensure that every student should reach all the outcomes. Feedback, furthermore, assists identify learners with difficulties with critical thinking and decision-making skills (11).

Table 3: Example of a checklist for the tutor (for regular participation of students)

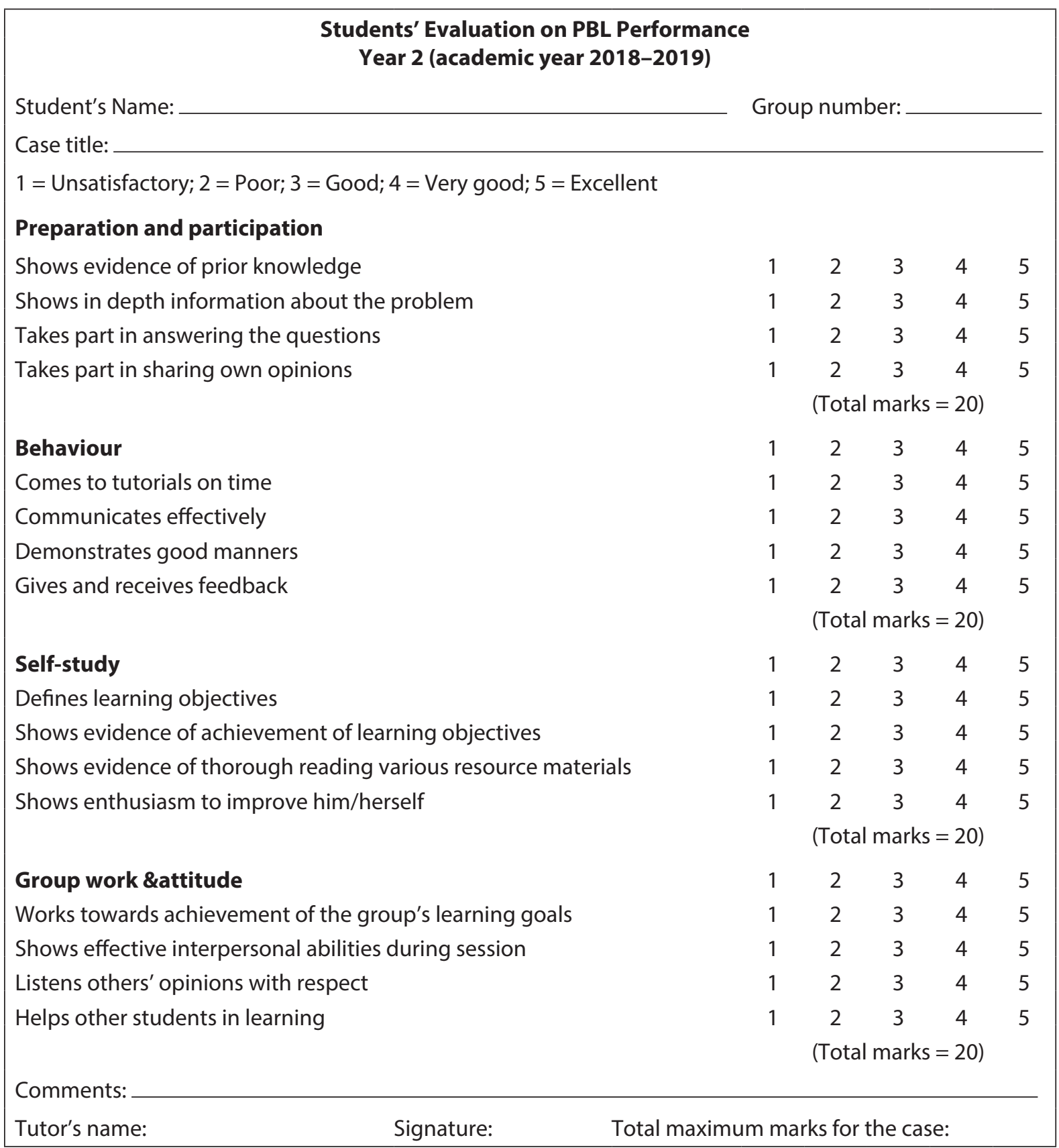


Table 4: Example of a checklist for the students (self-assessment)

\section{Students' Evaluation on PBL Performance}

Year 2 (academic year 2018-2019)

Student's Name: Group number:

Case title:

1 = Unsatisfactory; 2 = Poor; 3 = Good; 4 = Very good; 5 = Excellent

\section{Knowledge}

Having comprehensive knowledge about problem

Recognising professional and unprofessional attributes

Knowing the impact of such behaviours on exam results

Knowing what to do in such a condition

\section{Decision making}

Making appropriate decisions in such a problem

Formulation of a reasonable conclusion for the problem

Performing along the professional attributes

Avoiding unprofessional behaviours

\section{Self motivation}

Having own learning objectives

Coming to the session well prepared

Knowing my weak areas

Making efforts to improve

\section{Attitudinal}

Coming on time

Having integrity to take stand for my point of view

Studying for each session

Handling over my work on time

$\begin{array}{ccccc}1 & 2 & 3 & 4 & 5 \\ 1 & 2 & 3 & 4 & 5 \\ 1 & 2 & 3 & 4 & 5 \\ 1 & 2 & 3 & 4 & 5 \\ & (\text { Total marks }=20) & \end{array}$

$($ Total marks $=20)$

$\begin{array}{ccccc}1 & 2 & 3 & 4 & 5 \\ 1 & 2 & 3 & 4 & 5 \\ 1 & 2 & 3 & 4 & 5 \\ 1 & 2 & 3 & 4 & 5 \\ 1 & 2 & 3 & 4 & 5 \\ \text { (Total marks }=20) & \end{array}$

marks $=20$

$\begin{array}{lllll}1 & 2 & 3 & 4 & 5\end{array}$

$\begin{array}{lllll}1 & 2 & 3 & 4 & 5\end{array}$

$\begin{array}{lllll}1 & 2 & 3 & 4 & 5\end{array}$

$\begin{array}{lllll}1 & 2 & 3 & 4 & 5\end{array}$

$\begin{array}{lllll}1 & 2 & 3 & 4 & 5\end{array}$

(Total marks $=20)$

$\begin{array}{llll}2 & 3 & 4 & 5\end{array}$

$\begin{array}{lllll}1 & 2 & 3 & 4 & 5\end{array}$

$\begin{array}{lllll}1 & 2 & 3 & 4 & 5\end{array}$

$\begin{array}{lllll}1 & 2 & 3 & 4 & 5\end{array}$

$\begin{array}{lllll}1 & 2 & 3 & 4 & 5\end{array}$

$($ Total marks $=20)$

Total maximum marks for the case:

\section{Ask Yourself, "How Details of the Curriculum Should be Communicated?"}

Once the timetable is finalised, the detailed programme about PBL shall be announced/ informed to all students through emails, college notice board and e-learning blackboard.
A dedicated secretary (at student academic affairs or curriculum department) shall carry out all means to distribute the programme details and communicate with the student well before the actual sessions. The student class leaders are also to be notified and they also can spread the programme information among their group students. Moreover, this timetable may also be included in the student study guide, distributed to all students at the start of the semester. 


\section{Ask Yourself, "What Educational Environment or Climate Should be Fostered?"}

Students are supported to have eloquent and meaningful learning about the subject of professionalism which later on they will be utilising and practising in their every day's work. This high-grade learning, then, shall help them achieve the acquisition of knowledge in a way allowing practising it in real life (12). Therefore, to make sure that the students have meaningful learning about this subject, it is indispensable to create a non-threatening environment (that's why PBL is the choice) where they may freely advocate their ideas and discuss among the group with full confidence for what they do know and what they don't. PBL serves as an informal learning atmosphere, encouraging the participant to have full interaction thus fostering deep learning.

This shall guide and stimulate students' thinking in directions that ultimately lead them towards a useful exploration about the problem. But the most important factor that clicks is encouraging students to have as much interaction during the session as possible, and this is again a tutor's role to not to neglect any student if he/she is hesitant to talk and participate during a PBL session (refer Figure 3).

\section{Ask Yourself, "How the Process Should be Managed?"}

Here all stakeholders (e.g. vice-dean of student affairs, department of medical education, senior and trained faculty, educational block-chairs/course organisers, and educational block-committees and last but not the least the student representatives) need to take responsibility and play their roles. Starting with the vice-dean's (or any other concerned and authoritative personnel) official/written permission is achieved. Next step is for the remaining players to have to put their efforts together, e.g. Department of Medical Education is responsible for arranging the periodical hands-on training workshops for the small group facilitators/tutors where faculty members learn and share their experience in the construction and the conduction of the PBL.

Block-chairs/course organisers are responsible to provide/recommend the required number of faculty members who really are devoted and enthusiastic to be a small group and PBL tutor, and the rule of thumb is "don't force anyone who is not willing to be so", because these sessions (PBL) really necessitate enthused and dedicated members.

Block committee might be obliged to meet with a designated specialist from Department of Medical Education at the beginning of the semester to finalise the PBL cases. Towards the end of the semester, the feedback sessions are to be arranged to look into the details as how all the education sessions perform. The presence of students' representative shall make it valid to judge the performance and efficacy of these sessions.

Department of Medical Education, through the support of the faculty development unit shall arrange to organise hands-on workshop at the start of the semester, where tutors learn the PBL process in detail with

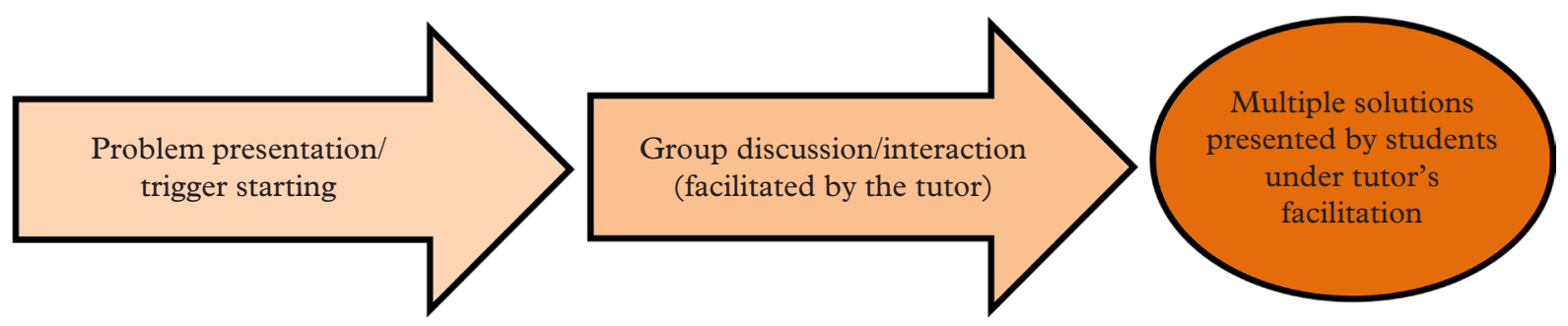

Figure 3: Flow of the PBL session. 
the full understanding and knowledge of the curriculum and so be able to develop their facilitation skills which in fact is a prerequisite to have an effective PBL session.

\section{WHY PBL?}

The approach to incorporate PBL in professionalism course, as presented in this paper, shall supplement the impending of accomplishing the educational goals any healthcare institute may dream. This shall also help to reinforce the level of professionalism with in medical education context. Medical professionalism being the heart and soul of medicine, through this approach shall receive ample attention, which will enable undergraduate medical student to get professional attributes indoctrinated as well as the same shall serve in their post graduate tenure as equally essential as any other element of medical education.

Any health institute in the quest of achieving accreditation status or to heighten the educational standards, and as a part of its strategic plan towards the achievement of such goals, PBL has shown ample evidence from the literature to be very reassuring. Therefore, to be focused on achieving a progressive shift in the way, medical education could be delivered, moving from didactic lecture pattern towards problembased approach is a must.

\section{Some Noticeable Features of PBL}

(a) Trigger really triggers: $\mathrm{PBL}$ case scenarios if well built (with special care on triggers) may foster students' active learning. During a PBL session, students use "triggers" from clinical scenarios to outline their own learning objectives which are refined in group discussions (13). Additionally, the subject knowledge is developed in an active and self-directed way (14). (b) Passive to active learning (Studentcentered): Most importantly, it is student-centred enabling them to formulate the learning goals. The more the students are contributing in goal setting the more positive outcome is sure to arrive. During the PBL sessions, it is easier for students to learn actively using the problem as a focus for their knowledge gap.

(c) Critical thinking and reasoning promotes deep learning: PBL offers openings of deep learning, qualifying the students attaining objectives, simply because there is more than just memorising the concepts of the subject, and thus allows students to learn material by smearing progressions of reasoning rather than by rote memorisation (15). PBL does promote students' critical thinking and reasoning by allowing them to explore deeper with the provision of discussion. PBL discourses the aptitude to think judgementally and be able to evaluate and resolve complex, real-world problems (16).

(d) Learn to learn: This course titled "Professionalism in Medicine" focuses on imparting the knowledge and skills about many professional attributes and guide students to develop them. This is achieved through PBL that enables them to know what they know (metacognition/learn to learn). Professional attributes, e.g. teamwork, communication skills, integrity, trustworthiness; time management and above all the doctor-patient interaction; such and other attributes are best learnt within the spectrum of PBL due to its ability to let students depend on transferring the ideas and knowledge (which comes with teamwork, discussions, clinical reasoning and problem-solving activities within PBL). In clinical practice, students need to be equipped with effective communication 
skills, ability to be a good team member, which is achievable through PBL. These features make it a preferred tool for medical educationist $(17,18)$. PBL teaching addresses the aptitude to establish multipurpose and operative communication skills, both verbal and written (16).

(e) Presentation: Stimulus material; during PBL, students are presented with the case, in real life/clinical context, which being interesting plays vital role in developing students' knowledge around it. This makes the learning interesting, factual, easy going and expounded.

(f) Integration: Selecting PBL for the course of professionalism gives students the best possible ways of learning depending on its ability to integrate well with other teaching strategies as well as with other teaching blocks. Therefore, students are able to activate the prior knowledge and use it to build further milestones.

(g) Learning guidance: Although during PBL sessions, students do make mistakes yet learn from them. Because only PBL is a method where the teacher/facilitator/tutor holds him/ herself from teaching and giving directly the correct information.

(h) Assessment of performance: Assessing the performance (as one of important Gagne's events of instructions); this is very crucial part of learning activities which leads towards the accomplishment of the objectives and this is best carried out by students (selfassessment checklists).

(i) Feedback and continuous improvement: Through acquiring the course aims and objectives, students develop skills in scientific reasoning, self-study and selfevaluation. Faculty is encouraged for providing a non-threatening feedback to the students and valued for continuing modification and improvement of the course and all this is why the PBL is selected.

(j) Motivation towards lifelong learning: For all above merit, the students are motivated and enjoy that in turn make it possible to get ready for adult and lifelong learning.

\section{CONCLUSION}

The effectiveness of developing the PBL method to teach professionalism is evident, which stimulates an environment that more aware about professional attitudes and behaviours. Moreover, if this strategy is applied in full context of honestly answering Harden's ten questions shall stimulate teaching and learning about professional behaviour even beyond the curriculum. An educational strategy, as this will prepare our students to be future leaders in our fast varying professional environment.

\section{REFERENCES}

1. Harden RM. Ten questions to ask when planning a course or curriculum. Med Educ. 1986;20(4). https://doi.org/ 10.1111/j.1365-2923.1986.tb01379.x

2. American Board of Internal Medicine. Project professionalism, ABIM Committee on Evaluation of Clinical Competence, Philadelphia PA. 1995 [cited 10 November 2018]. Available from: https:// medicinainternaucv.files.wordpress. com/2013/02/project-professionalism.pdf

3. Nicholas GP, Dana PH, Dan JH, Alan RS, Karen PW, Beardsley RS, Hershey SB, Jennifer LA. Report of the AACP professionalism task force, May 2011. Am J Pharm Educ. 2011;75(10):S4. https://doi. org/10.5688/ajpe7510S4 
4. Swick HM. Toward a normative definition of medical professionalism. Acad Med. 2000;75(6):612-6. https://doi.org/10.1097/ 00001888-200006000-00010

5. Bryden P, Ginsburg S, Kurabi B. 2010. Professing professionalism: are we our own worst enemy? Faculty members' experiences of teaching and evaluating professionalism in medical education at one school. Acad Med. 85:1025-34. https://doi.org/10.1097/ ACM.0b013e3181ce64ae

6. Hafferty FW, Castellani B. The increasing complexities of professionalism. Acad Med. 2010; 85(2):288-301. https://doi.org/ 10.1097/ACM.0b013e3181c85b43

7. Kandi V, Basireddy PR. Creating a student-centered learning environment: implementation of problem-based learning to teach microbiology to undergraduate medical students. Cureus. 2018;10(1):e2029. https://doi.org/10.7759/ cureus. 2029

8. Van Mook WNKA, Van Luijk SJ, O'Sullivan $\mathrm{H}$, Wass V, Schuwirth LW, Van der Vleuten CP. General considerations regarding assessment of professionalism behaviour. European Journal of Internal Medicine. 2009;20(4):e90-5. https://doi.org/10.1016/j. ejim.2008.11.011

9. Chastonay P, Brenner E, Peel S, Guilbert J-J. The need for more efficacy and relevance in medical education. Med Educ. 1996;30:235-8. https://doi. org/10.1111/j.1365-2923.1996.tb00823.x

10. Harden RM, Sowden S, Dunn WR. Educational strategies in curriculum development: the SPICES model. Med Educ. 1984;18(4):284-97. https://doi.org/ 10.1111/j.1365-2923.1984.tb01024.x

11. Elizondo-Montemayor LL. Formative and summative assessment of the problembased learning tutorial session using a criterion-referenced system. Medical Science Educator. 2004;14(1):7-14.
12. Mintzes JJ, Wandersee JH. Reform and innovation in science teaching: a human constructivist view. In: Mintzes JJ, Wandersee JH, Novak JD, editors. Teaching science for understanding. San Diego, CA: Academic; 1997. p. 29-58. https://doi. org/10.1016/B978-012498360-1/50003-9

13. Wood DF. Problem based learning. British Medical Journal. 2003;326:328-330. https:// doi.org/10.1136/bmj.326.7384.328

14. Maudsley G. Do we all mean the same thing by "problem-based learning"? A review of the concepts and a formulation of the ground rules. Acad Med. 1999;74:178-85.

15. Chakravarty M, Latif NA, Abu-Hijleh MF, Osman M, Dharap AS, Ganguly PK. Assessment of anatomy in a problembased medical curriculum. Clin Anat. 2005;18:131-6.

16. Diemers $A D$, van de Wiel MW, Scherpbier AJ, Baarveld F, Dolmans DH. Diagnostic reasoning and underlying knowledge of students with preclinical patient contacts in PBL. Med Educ. 2015;49(12):1229-38. https://doi.org/10.1111/medu.12886

17. Prince KJ, van Eijs PW, Boshuizen HP, Vleuten CP van der, Scherpbier AJ. General competencies of problem-based learning (PBL) and non-PBL graduates. Med Educ. 2005;39:394-401. https://doi.org/10.1111/j. 1365-2929.2005.02107.x

18. Cohen-Schotanus J, Muijtjens AM, Schonrock-Adema J, Geertsma J, Vleuten $\mathrm{CP}$ van der. Effects of conventional and problem-based learning on clinical and general competencies and career development. Med Educ. 2008;42:256-65. https://doi.org/10.1111/j.1365-2923.2007. 02959.x 